\title{
RESPONSES OF ECONOMIC NEWS ON ASSET PRICES: A STUDY OF INDIAN STOCK INDEX FUTURES
}

\author{
AMEET KUMAR BANERJEE ${ }^{*}$, H. K PRADHAN 2 \\ 1. Xavier Institute of Management, Xavier University, India \\ 2. XLRI -Xavier School of Management, India
}

* Corresponding Author: Dr Ameet Kumar Banerjee, Associate Professor, Xavier Institute of Management, Xavier University, Bhubaneswar, Odisha - 751 013, India

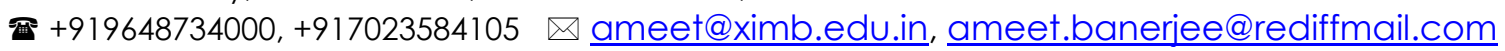

\begin{abstract}
The study examines the role of economic news surprises on the volatility of the returns of the Indian Index futures market. Theoretical literature posits that news arrivals influence price discovery. In similar lines, we investigated the relationship between economic news releases, trading activity variables, and returns volatility. We find that economic news surprises and trading activity variables significantly affect returns volatility. However, among volume and news surprises, economic news surprises are much stronger informational signals, and the news surprises effects are found seemingly asymmetric in the index futures contract.
\end{abstract}

Keywords: Economic news surprises; asymmetric effect; exponential GARCH; returns volatility

\section{Introduction}

Recently news as a source of information signal influencing asset price discovery in financial markets drew extensive attention. The daily deluge of news information, whether related to corporate earnings, news of macroeconomic nature such as exchange rate or interest rate or political ones which impinges on financial markets that may have an atypical but different degree of influence on a particular asset class. For instance, news of macroeconomic nature has a profound impact on the currency market than the stock and the bond market (Andersen et al., 2007). Moreover, an excessive inflow of information may also be chaotic as investors will fail to decode the information content of the news, resulting in an imprecise estimation about the state of the economy in the future and the asset prices.

This paper contributes to the literature by examining a particular class of news, that is, the economic news that is released in the public domain to a somewhat elusive asset class such as the stock index futures. Moreover, we specifically explore whether surprises in the news segment affects asset price, through return and volatility of the index futures contracts. However, most of the empirical studies have focused their attention on mature markets providing a nuanced view of the informational role of the news surprises (Andersen et al., 2007; Elder et al., 2012; Paiardini, 2014). However, there is still exists void in the context of the emerging market in understanding the informational role of news signals, whose market structure vastly differs from that of the mature markets.

Past literature has also attempted to employ volume or open interest (volume proxies) as a source of the market signal testing "mixture of distribution" hypothesis (Epps and Epps, 1976; Harris, 1986). Bessembinder and Seguin (1993) have also used open interest as a proxy to test the market depth. In this paper, we explored the importance of information signals. We attempted to unravel valuable insights into asset price discovery and volatility, considering six news variables that are of concern 
to both investors and policymakers and volume proxies serving as additional sources of information signals. Moreover, the established consensus in the literature claims that news and especially surprises in the press releases significantly affect financial markets both in terms of asset return and their volatility (Ho et al., 2017; Nowak et al., 2011).

In this paper, we tried to address three essential issues:

1. What is the impact of economic news on returns and volatility

2. Does volume serve as an information proxy?

3. Among volume proxies and economic news, which are stronger signals of information flow?

In our work, to test the above issues, we have identified six different news releases such as dividend yield, put-call ratio, exchange rate, repurchase rate (Repo), index of industrial production (IIP) and wholesale price index (WPI), considered as the most important news serving as a proxy for information arrivals on index futures returns and their volatility. The logic to use these variables was to be representative of vastly different kinds of news categories, in the broader areas of corporate news (dividend yield), sentiment indicator (put-call ratio), and macroeconomic news (exchange rate, Repo, IIP, and WPI). We also included trading volume and open interest as proxies for information flow as traders use these endogenous variables as indicators of market trends.

Interestingly our analysis provides newer insights. First, we found that news surprises significantly affect the volatility of index futures returns. In particular, news about dividend yield, exchange rate, the repo rate, and index of industrial production (IIP) has a significant effect on returns volatility. Additionally, trading volume and open interest significantly affect return volatility when used as a proxy for informational arrivals. However, when integrated with economic news volume, proxies lose their significance, indicating that economic news provides much stronger signals of information flows.

The rest of the article proceeds as follows. In section II, we review the related literature and develop our research hypothesis. In section III, we present the data characteristics. Estimation methodology is presented in Section IV, followed by the empirical results in Section V. The conclusion, findings, and scope for the future are in section VI.

\section{Relevant literature review and hypotheses}

There is a great deal of interest in examining the market reaction to the news. In line with the theoretical underpinning of Kim and Verrecchia (1991), investor apriori has some expectation about the news and trade accordingly. Whenever the news sprung surprises, the traders revise their beliefs and revisit trading. Similarly, Kim and Verrecchia (1997) and Nowak et al. (2011) argued that news releases cause information asymmetry leading to heterogeneous responses among traders, thereby news impact on volatility is found to dominate security prices. Moreover, Garcia (2013) and Gospodinov and Jamali (2015) reported that news of macroeconomic nature tended to affect stock prices and stock market volatility and witnessed an asymmetric response to monetary policy shocks. To get further insights, we derive a list of potential news variables with relevant literature, as presented in Table 1, to analyze the impact of these macroeconomic variables on the volatility of index futures.

Based on the current literature, we test the following hypothesis:

$H_{1}$ : Economic news surprises affect the volatility of the returns and have an asymmetric impact.

Bessembinder and Senguin (1993), studying eight futures markets, provided shreds of evidence of a positive relationship between futures return volatility and trading volume proxies. By bifurcating the trading volume proxies into expected, and unexpected components were the unexpected component is synonymous with unanticipated changes in contract positions. They reported 
particularly that the influence of unexpected volume shocks contributing more to price volatility than the expected volume. The findings of the study supported that expected open interest is negatively related to price volatility in the futures market, indicating that increased open interest position is more related to lower price volatility. Daigler and Wiley (1999), and Hong and Yogo (2012), by examining index futures contracts obtained analytical results that confirm the empirical findings of Bessembinder and Seguin (1993). From the results of the above studies, it is apparent that trading activity variables such as volume and open interest are an essential determinant of futures price volatility.

\section{Table 1: List of Macroeconomic Variables}

\begin{tabular}{lll}
\hline Serial No. & Variable & Relevant Literature \\
\hline 1 & Dividend Yield & Gospodinov and Jamali (2015) \\
2 & Sentiment Indicator (Put Call Ratio) & Brzesczynski et al. (2015) \\
3 & Exchange Rate & Karali and Power (2013) \\
4 & Short term Interest Rate (REPO) & Frankel (2014) \\
5 & Inflation rate (WPI) & Balduzzi et al. (2001) \\
6 & Industrial Index of Production (IIP) & Karali and Power (2013) \\
\hline
\end{tabular}

Hence the following hypotheses are tested:

$\mathrm{H}_{2}$ : Trading activity variable of the expected volume relates positively with returns volatility

$\mathrm{H}_{3}$ : Trading activity variable of the unexpected volume relates positively with returns volatility

$\mathrm{H}_{4}$ : Trading activity variable of expected open interest (OI) relates negatively with returns volatility

$\mathrm{H}_{5}$ : Trading activity variable of unexpected open interest (OI) relates negatively with returns volatility

Most of these studies primarily investigated either the determinants of volatility or the effect of trading volume variables on volatility. However, given the significant role of trading volume, open interest, and news surprises on returns volatility, we integrated these variables in the same model and followed by their interaction effects in the Indian index futures market. We pose two critical questions: does economic news surprises determine the return volatility of the index futures contract in India, and whether there is an interaction effect of trading volume, open interest with economic news surprises on volatility?

Hence the following hypothesis is tested:

$\mathrm{H}_{6}$ : News surprises moderates the relationship between trading volume and open interest on returns volatility

We examine the six hypotheses as stated above to uncover valuable information and draw meaningful insights into the sensitivity of index futures markets of India to economic news shocks. 


\section{Data Characteristics}

We have used daily data of Nifty 50 futures contract as traded at the National Stock Exchange (NSE), India, from 02 January 2011 to 29 December 2016. The index futures prices are nearby month contracts, which are the most actively traded to avoid any maturity effect biases (Chen and Tai, 2014). Further, we roll over the nearby contract into the second-nearest contract on the expiration date for continuity.

The returns are calculated for the index futures contracts by taking the natural logarithmic difference in the price levels.

$$
R_{t}=\left(\ln P_{t}-\ln P_{t-1}\right)
$$

where $P_{t}$ is the closing price of Nifty 50 futures contract at date $t$. The source of economic variables which are part of the study is from the handbook of statistics of Reserve Bank of India (RBI), and Bloomberg database.

Table 2: Descriptive Statistics of daily CNX Nifty 50 Futures contracts

\begin{tabular}{lccr}
\hline & Returns & Total Volume (Lacs) & Open Interest \\
\hline Mean & 0.044706 & 864997.60 & 17997344 \\
Median & 0.054276 & 822962.60 & 17763900 \\
SD & 1.005714 & 325954.20 & 4588278 \\
Max & 3.608335 & 3612235.00 & 34347975 \\
Min & -6.208278 & 43095.06 & 5220225 \\
Skewness & -0.294988 & 1.504110 & 0.195538 \\
Kurtosis & 5.071054 & 10.15625 & 3.635052 \\
Jarqure-Bera Statistics & 239.4025 & 3110.989 & 28.71549 \\
& $(0.0000)^{*}$ & $(0.0000)^{*}$ & $(0.0000)^{*}$ \\
\hline
\end{tabular}

Note: $*, * *$ and $* * *$ represents significance level at $1 \%, 5 \%$ and $10 \%$.

Table 3: Tests on time series property of CNX Nifty 50 Futures Contract

\begin{tabular}{|c|c|c|c|c|}
\hline \multicolumn{5}{|l|}{ Unit Root Test } \\
\hline & & Panel A & Panel B & Panel C \\
\hline Tests Statistics & & ADF Test & PP Test & KPSS Test \\
\hline Return Series & & $-33.93275^{*}$ & $-33.91017^{*}$ & $0.16550 *$ \\
\hline \multirow[t]{3}{*}{ Critical Values } & $1 \%$ & -3.43541 & -3.43541 & 0.739000 \\
\hline & $5 \%$ & -2.86366 & -2.86366 & 0.463000 \\
\hline & $10 \%$ & -2.56795 & -2.56795 & 0.347000 \\
\hline \multicolumn{5}{|c|}{ Heteroscedasticity Test } \\
\hline \multicolumn{5}{|c|}{ Ljung- Box Statistics } \\
\hline$Q(36)$ & & $\begin{array}{l}40.161 \\
(0.291)\end{array}$ & & \\
\hline
\end{tabular}

Table 2 reports the descriptive statistics of the returns, trading volume, and open interest of the Nifty 50 futures contract. The mean daily return on Nifty 50 futures is 0.04470 , with returns standard deviation 1.0057 per day. The skewness is -0.29498 , indicating that the returns series is negatively skewed, and the kurtosis value of 5.07105 is an indication that the unconditional distribution of the returns exhibits fat tails and excess kurtosis against the normal distribution, which is also confirmed by the Jarque- 
Bera (JB) statistics. The mean and standard deviation of the volume are 864,997.0 (lacs) and $325,954.20$ (lacs), and that of open interest is $17,997,344.0$ and $4,588,278.0$. The skewness and kurtosis of the volume are 1.50411 and 10.51625, and the corresponding value for open interest is 0.19553 and 3.63505, respectively, thereby clearly showing deviation from normality which is also supported by Jarque-Bera test. Thus, the rejection of normality characteristic is evident in all three series of returns, volume, and open interest. Figure 1 presents the times series plot of closing prices, return, volume, and open interest.

Figure 1: Time series plot of daily closing prices, returns, daily trading volume and open interest of Nifty 50 index futures contract

PRICE

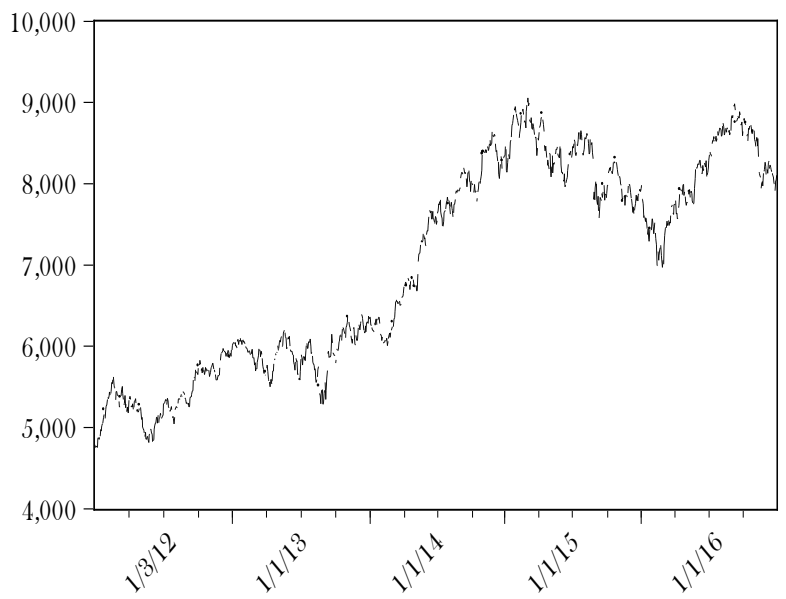

VOLUME

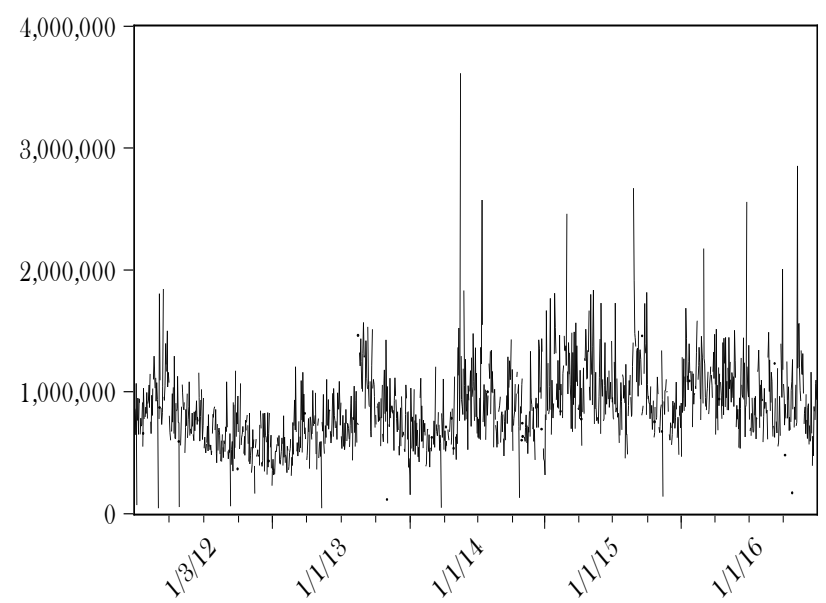

RETURNS

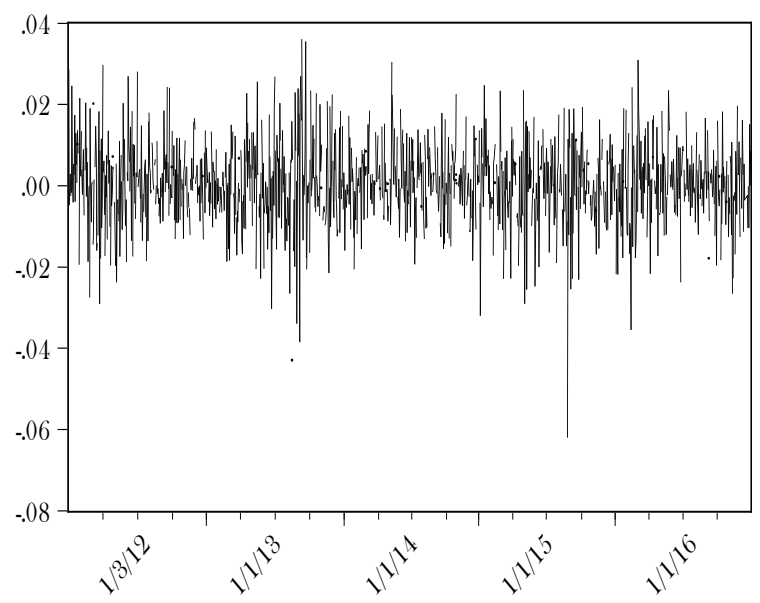

OPEN_INTEREST

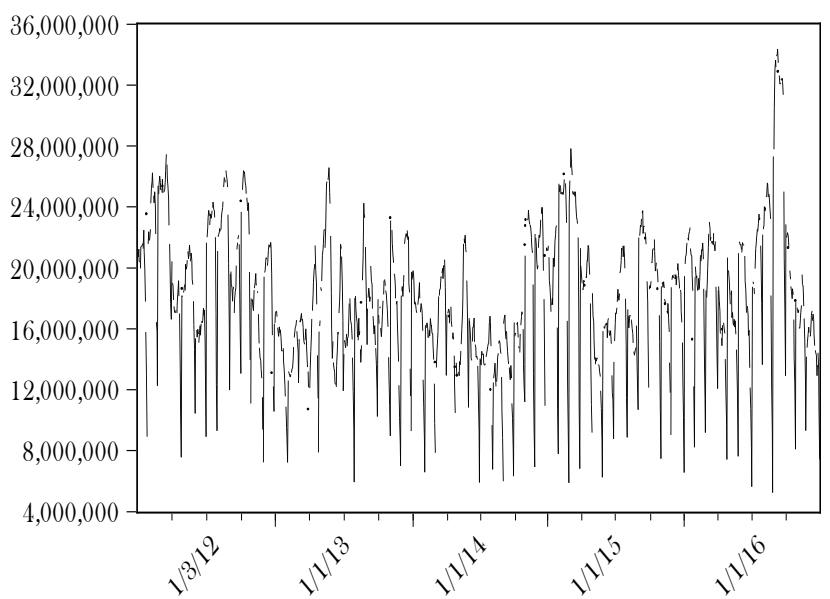

\section{Methodology}

The study tests the impact news surprises rather than their absolute released values by the official agencies, as the market participants are expected to trade in stock index futures based on the expected news arrival. We first constructed the forecasted value of the news variable using an ARIMA model. We then obtained the difference between the actual news and their forecasted values to derive the surprise or unexpected news component. As units of measurement differ across the news variables, we standardized the news surprises as derived following Balduzzi et al. (2001) for any news type $k$ on day $t$, the calculation of news surprise (NS) is as follows: 


$$
N S_{k, t}=\frac{A_{k, t}-F_{k, t}}{\sigma_{k}}
$$

where $A_{k, t}$ is the actual value of a news release of type $k$ at time $t$ and $F_{k, t}$ is the forecasted value, and $\sigma_{k}$ is the standard deviation $k^{\text {th }}$ news surprise component.

In the present study, we adopted an exponential GARCH (EGARCH) model of Nelson (1991) to examine the relative impact of news surprises on the volatility of the returns of the index futures, by regressing news surprises on return and its conditional volatility. In general, the past studies have modeled the news impact on the mean return. Still, only a limited number of studies have tried to examine if there is any impact on the conditional volatility of return. To capture the asymmetric effect, we have integrated the news surprises variables in both the mean and return equations. The model specification of the EGARCH model is given by:

$$
\begin{gathered}
R_{t}=\tau_{c}+\tau_{\text {lag }} R_{t-1}+\sum_{k=1}^{m} \theta_{- \text {venews }}-v e N S_{k, t}+\sum_{k=1}^{m} \theta_{+v e n e w s}+v e N S_{k, t}+\varepsilon_{t} \\
\log \left(\sigma_{t}^{2}\right)=\delta_{c}+\delta_{\varepsilon, 1}\left|\frac{\varepsilon_{t-1}}{\sigma_{t-1}}\right|+\delta_{\varepsilon, 2}\left(\frac{\varepsilon_{t-1}}{\sigma_{t-1}}\right)+\delta_{\text {lag }} \log \left(\sigma_{t-1}^{2}\right)+\sum_{k=1}^{m} \gamma_{-v e n e w s, k}-v e N S_{k, t}+\sum_{k=1}^{m} \gamma_{+ \text {venews }, k}+v e N S_{k, t}
\end{gathered}
$$

where $\varepsilon_{t}=z_{t} \sigma_{t}$ and $z_{t} \sim N(0,1), R_{t}=$ the returns of the futures contract; $\varepsilon_{t}=$ The error term is assumed $\sim\left(0, \sigma_{t}\right) ; \sigma_{t}=$ The conditional volatility; $N S_{k, t}=$ the component of news surprises.

The coefficient $\delta_{\text {lag }}$ measures the persistence of the conditional variance. The coefficients $\delta_{\varepsilon, 1}$ and $\delta_{\varepsilon, 2}$ represents the impact of lagged errors on the current conditional variance. While a negative $\delta_{\varepsilon, 2}$ indicates that the negative shocks have a larger effect on the conditional variance. In contrast, a significant $\gamma$ suggests that the news surprises have a direct impact on the conditional variance on the release dates. While $\gamma_{- \text {venews }, k}$ and $\gamma_{+ \text {venews }, k}$ are the coefficients of negative and positive news on volatility.

\subsection{Modeling the impact of volume on volatility}

Following Gulen and Mathew (2000), whether trading volume and open interest affect volatility, we integrated volume and open interest (expected and unexpected component) into the EGARCH model as a proxy for predicting the arrival of unobservable information (Lamourerex and Lastrapes, 1990; Daigler and Wiley, 1999). However, Lamourerex and Lastrapes (1990) have reported that the volatility persistence significantly diminishes with the inclusion of trading activity variables in the conditional variance. To capture how the responses of volatility are by adding the expected and unexpected components of volume proxies to the EGARCH framework. The modified model is as follows:

$$
\begin{aligned}
& \log \left(\sigma_{t}^{2}\right)=\delta_{c}+\delta_{\varepsilon, 1}\left|\frac{\varepsilon_{t-1}}{\sigma_{t-1}}\right|+\delta_{\varepsilon, 2}\left(\frac{\varepsilon_{t-1}}{\sigma_{t-1}}\right)+\delta_{\text {lag }} \log \left(\sigma_{t-1}^{2}\right)+\delta_{\text {Exp_Vol }} \text { Exp_Vol }_{t}
\end{aligned}
$$

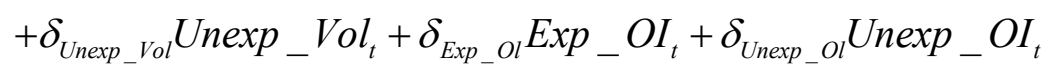

where $\delta_{E x p_{-} V_{0 l}}$ and $\delta_{\text {Unexp_Vol }_{\text {Vol }}}$ are the coefficients of expected and unexpected volume and $\delta_{\text {Exp_ } O I}$ $\delta_{\text {Unexp_oI }}$ are the coefficients expected and unexpected open interest. 


\section{Empirical results}

Table 4 presents the coefficients estimates of $\delta_{\varepsilon, 1}$ and $\delta_{\varepsilon, 2}$. In contrast, the coefficient $\delta_{\varepsilon, 1}$ is positive $(0.2104)$ indicating that new information leads to increasing volatility, the coefficient of asymmetric $\delta_{\varepsilon, 2}$ estimated in the EGARCH framework is negative $(-0.0500)$, which is indicative of the asymmetric return-volatility relationship. These findings are consistent with the studies of Chen et al. (2011) who posited that negative impacts are more significant than positive impacts in the context of the volatility of index futures.

Table 4 further provides useful insights into the relationship between economic news releases and returns volatility; among the news items that have an impact on volatility are dividend yield, exchange rate, the repo rate, and index of industrial production (IIP). Although both types of negative and positive news surprises have significant impacts, the magnitudes of their effects are statistically different from each other (Hypothesis 1), that is $\gamma_{+ \text {venews }} \neq \gamma_{\text {-venews }}$, as observed from the Wald's tests.

\section{Table 4: Estimated EGARCH $(1,1)$ model with surprises in economics news releases components}

\begin{tabular}{clll}
\hline Variance Equation & & & \\
\hline Coefficients & Values & z- Statistics & P values \\
\hline$\delta_{\mathrm{c}}$ & -10.8185 & -11.8135 & 0.0000 \\
$\delta_{\varepsilon, 1}$ & 0.2104 & 2.8557 & 0.0043 \\
$\delta_{\varepsilon, 2}$ & -0.0500 & -0.9213 & 0.3568 \\
$\delta_{\text {lag }}$ & 0.0778 & 0.9659 & 0.3340 \\
$\gamma_{\text {-venews,div_yield }}$ & -0.6642 & -4.9208 & 0.0000 \\
$\gamma_{\text {+venews,div_yield }}$ & 0.8970 & 8.0438 & 0.0000 \\
$\gamma_{\text {-venews,PCR }}$ & -0.0141 & -0.1242 & 0.9011 \\
$\gamma_{\text {+venews,PCR }}$ & 0.0270 & 0.2542 & 0.7993 \\
$\gamma_{\text {-venews,ex_rate }}$ & 0.1582 & 1.5735 & 0.1156 \\
$\gamma_{\text {+venews,ex_rate }}$ & 0.1894 & 1.9429 & 0.0520 \\
$\gamma_{\text {-venews,repo }}$ & -0.1748 & -2.0509 & 0.0403 \\
$\gamma_{\text {+venews,repo }}$ & -0.0885 & -1.1368 & 0.2556 \\
$\gamma_{\text {-venews,wpi }}$ & 0.0731 & 1.4805 & 0.1387 \\
$\gamma_{\text {+venews,wpi }}$ & -0.1019 & -1.5734 & 0.1156 \\
$\gamma_{\text {-venews,iip }}$ & 0.1731 & 4.0087 & 0.0001 \\
$\gamma_{\text {+venews,iip }}$ & -0.1396 & -1.7957 & 0.0725 \\
Adjusted R2 & 0.7582 & & \\
\hline
\end{tabular}

Note: The results of the above table is computed using the following equation

$$
\begin{aligned}
& R_{t}=\tau_{c}+\tau_{\text {lag }} R_{t-1}+\sum_{k=1}^{m} \theta_{- \text {venews }}-v e N S_{k, t}+\sum_{k=1}^{m} \theta_{+ \text {venews }}+\text { veN } S_{k, t}+\varepsilon_{t} \\
& \log \left(\sigma_{t}^{2}\right)=\delta_{c}+\delta_{\varepsilon, 1}\left|\frac{\varepsilon_{t-1}}{\sigma_{t-1}}\right|+\delta_{\varepsilon, 2}\left(\frac{\varepsilon_{t-1}}{\sigma_{t-1}}\right)+\delta_{\text {lag }} \log \left(\sigma_{t-1}^{2}\right)+\sum_{k=1}^{m} \gamma_{- \text {venews }, k}-v e N S_{k, t}+\sum_{k=1}^{m} \gamma_{+ \text {venews }, k}+v e N S_{k, t}
\end{aligned}
$$

where $\varepsilon_{t}=z_{t} \sigma_{t}$ and $z_{t} \square N(0,1), R_{t}=$ the returns of the futures contract; $\varepsilon_{t}=$ The error term is assumed $\square\left(0, \sigma_{t}\right) ; \sigma_{t}$ $=$ The conditional volatility; $N S_{k, t}=$ The component of news surprises. While $\gamma_{- \text {venews }, k}$ and $\gamma_{+ \text {venews }, k}$ are the coefficients of negative and positive news on volatility. 
Moreover, particularly in case repo or exchange either negative or positive news surprises were found statistically significant at $5 \%$ and $10 \%$ level while news relating to dividend yield (1\%) and index of industrial production (IIP) $(1 \%, 10 \%)$ both categories of surprises in the news significantly impacted volatility with their appropriate level statistical significance. Interesting observations were that the coefficient values of negative news $\neq$ positive news indicating the presence of an asymmetric effect, thus finding support to our hypothesis $\mathrm{H}_{1}$. Figure 2 presents the responses of the index futures contract to economic news surprises.

\section{Figure 2: Responses of Index futures returns volatility to economic news surprises}

Dividend Yield

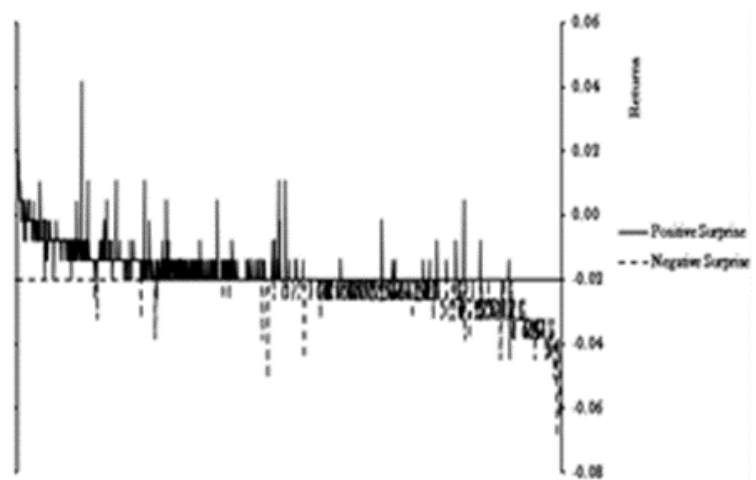

Exchange Rate

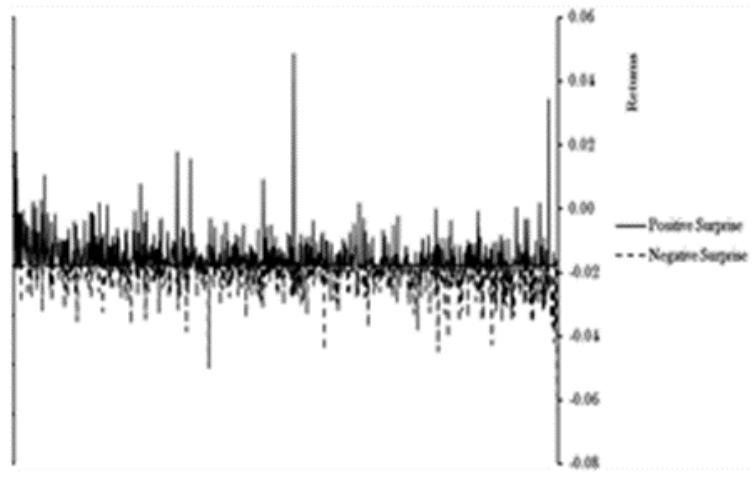

WPI

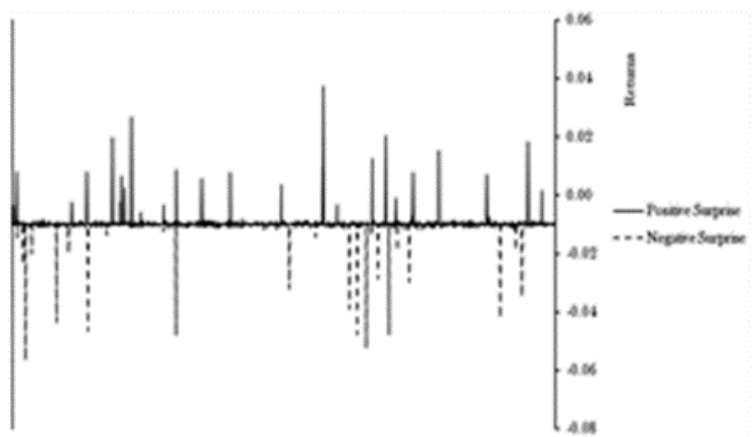

PutCall Ratio

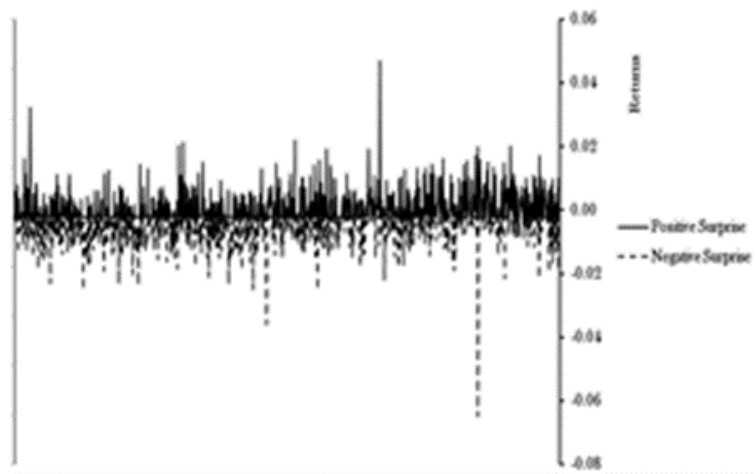

REFO

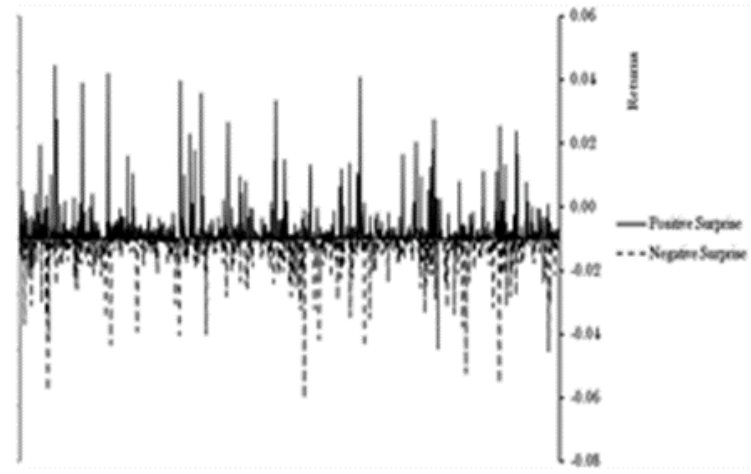

IIP

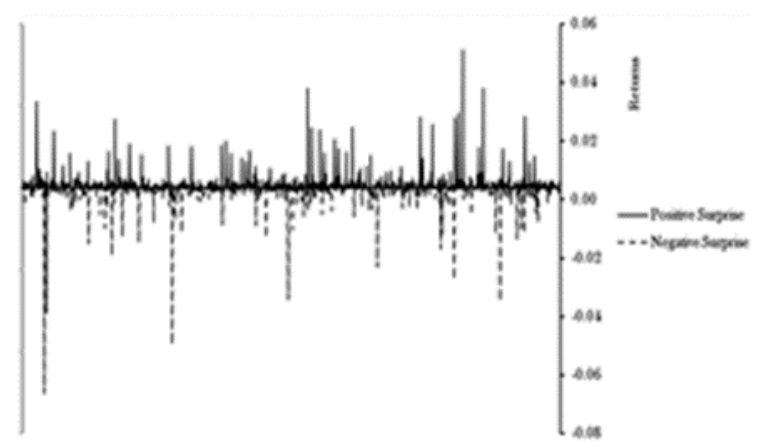




\subsection{The impact of trading activity variables on return volatility}

Table 5 reports the results of the estimated coefficient of trading activity variables. The coefficient of expected volume and unexpected volume in the volatility equation is found significant at a $1 \%$ level. At the same time, the magnitude and statistical significance show that the expected and unexpected trading volume has a heterogeneous effect on volatility. Most of the studies in the past reported a positive correlation between volume and volatility, for instance, Gallant et al. (1992) in stock markets or Bessembinder and Seguin (1993) in the futures market. Our results support the asymmetry return-volatility relationship by decomposing the trading volume into expected and unexpected components and hence finding support to hypothesis 2 and 3 . Furthermore, the coefficient of unexpected trading volume is more significant than expected volume, indicating that unexpected trading volume affects returns volatility more than the expected trading volume; these results are consistent with Frino et al. (2012) and Chen and Tai (2014). The coefficient estimates for both expected and unexpected open interest is positive statistically significant at a $1 \%$ level finding negative support for hypothesis 4 and supporting hypothesis 5 . These results of open interest are similar to the findings of Chen et al. (2011).

Table 5: Estimated EGARCH $(1,1)$ model with volume components

\begin{tabular}{cccc}
\hline Variance Equation & & & \\
\hline Coefficients & Values & z- Statistics & P values \\
\hline$\delta_{c}$ & -2.8367 & -2.7619 & 0.0057 \\
$\delta_{\varepsilon, 1}$ & 0.2013 & 3.2485 & 0.0012 \\
$\delta_{\varepsilon, 2}$ & -0.0749 & -1.9906 & 0.0465 \\
$\delta_{\text {lag }}$ & 0.7197 & 6.8360 & 0.0000 \\
$\delta_{\text {Exp_Vol }}$ & 3.2319 & 3.6970 & 0.0002 \\
$\delta_{\text {Unexp_Vol }}$ & 4.0119 & 5.7141 & 0.0000 \\
$\delta_{\text {Exp_ol }}$ & 2.9822 & 3.7484 & 0.0002 \\
$\delta_{\text {Unexp_ol }}$ & 1.5686 & 3.1825 & 0.0015 \\
Adjusted R2 & 0.0388 & & \\
\hline
\end{tabular}

Note: The above results are calculated using the following regression specification

$$
\begin{aligned}
& \log \left(\sigma_{t}^{2}\right)=\delta_{c}+\delta_{\varepsilon, 1}\left|\frac{\varepsilon_{t-1}}{\sigma_{t-1}}\right|+\delta_{\varepsilon, 2}\left(\frac{\varepsilon_{t-1}}{\sigma_{t-1}}\right)+\delta_{\text {lag }} \log \left(\sigma_{t-1}^{2}\right)+\delta_{\text {Exp_Vol Exp }} \text { Vol }_{t}
\end{aligned}
$$

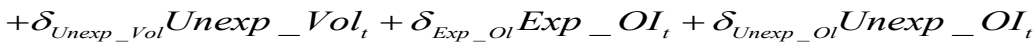

where $\delta_{\text {Exp_Vol }}$ and $\delta_{\text {Unexp_Vol }}$ are the coefficients of expected and unexpected volume an $\delta_{\text {Exp_OI }} \delta_{\text {Unexp_OI }}$ are the coefficients expected and unexpected open interest.

\subsection{The impact of trading activity variable and economic news surprises on volatility}

To explore among volume or macroeconomic news releases that are stronger in their impact on information flow, we regressed the trading activity variables of expected and unexpected volume and open interest on the macroeconomic news surprises in the EGARCH framework. As can be observed from Table 6, most of the trading activity variables lose their significance exception being unexpected open interest, which was found significant at a $10 \%$ level. However, most of the news variables retained their significance level. It can be observed from Table 6 that it is the economic news surprises, not the trading activity variable, which seems to serve as a more decisive factor affecting returns volatility, which is also indicated by the significant change in adjusted $R^{2}$ value to $76.6 \%$ 
Table 6: Estimated EGARCH $(1,1)$ model with volume and surprises in news releases

\begin{tabular}{|c|c|c|c|}
\hline Coefficients & Values & z- Statistics & P values \\
\hline$\delta_{\mathrm{c}}$ & -11.3030 & -10.5702 & 0.0000 \\
\hline$\delta_{\varepsilon, 1}$ & 0.1458 & 2.0633 & 0.0391 \\
\hline$\delta_{\varepsilon, 2}$ & -0.0462 & -0.8856 & 0.3758 \\
\hline$\delta_{\text {lag }}$ & 0.0403 & 0.4233 & 0.6721 \\
\hline$\delta_{\text {exp_vol }}$ & -0.0025 & -0.0064 & 0.9948 \\
\hline$\delta_{\text {unexp_vol }}$ & 0.5329 & 1.2876 & 0.1979 \\
\hline$\delta_{\text {exp_oi }}$ & 1.8535 & 1.2254 & 0.2204 \\
\hline$\delta_{\text {unexp_oi }}$ & 1.1826 & 1.9389 & 0.0525 \\
\hline$\gamma_{\text {-venews,div_yield }}$ & -0.6777 & -4.6401 & 0.0000 \\
\hline$\gamma_{+ \text {venews,div_yield }}$ & 0.9273 & 7.1973 & 0.0000 \\
\hline$\gamma_{\text {-venews,pcr }}$ & -0.1086 & -0.9413 & 0.3465 \\
\hline$\gamma_{+ \text {venews,pcr }}$ & 0.0488 & 0.4914 & 0.6231 \\
\hline$\gamma \gamma_{\text {-venews,ex_rate }}$ & 0.1727 & 1.6834 & 0.0923 \\
\hline$\gamma_{+ \text {venews,ex_rate }}$ & 0.2033 & 1.9939 & 0.0462 \\
\hline$\gamma_{- \text {venews,repo }}$ & -0.1417 & -1.6997 & 0.0892 \\
\hline$\gamma_{+ \text {venews,repo }}$ & -0.1026 & -1.2691 & 0.2044 \\
\hline$\gamma_{- \text {venews,wpi }}$ & 0.0532 & 1.1130 & 0.2657 \\
\hline$\gamma_{+ \text {venews,wpi }}$ & -0.0689 & -1.0294 & 0.3033 \\
\hline$\gamma_{\text {-venews,iip }}$ & 0.1444 & 3.0886 & 0.0020 \\
\hline$\gamma_{+ \text {venews,iip }}$ & -0.1185 & -1.5593 & 0.1189 \\
\hline Adjusted $\mathrm{R}^{2}$ & 0.7660 & & \\
\hline
\end{tabular}

Note: The results of the above table are calculated using the following specification

$$
\begin{aligned}
& \log \left(\sigma_{t}^{2}\right)=\delta_{c}+\delta_{\varepsilon, 1}\left|\frac{\varepsilon_{t-1}}{\sigma_{t-1}}\right|+\delta_{\varepsilon, 2}\left(\frac{\varepsilon_{t-1}}{\sigma_{t-1}}\right)+\delta_{\text {lag }} \log \left(\sigma_{t-1}^{2}\right)+\delta_{E x p_{-} V o l} E_{-x p} V_{\text {Vol }}+\delta_{\text {Unexp_Vol }} \text { Unexp }_{-} \text {Vol }_{t}+ \\
& \delta_{\text {Exp_ol }} \operatorname{Exp}_{-} O I_{t}+\delta_{\text {Unexp_ol }} U n \exp { }_{-} O I_{t}+\sum_{k=1}^{m} \gamma_{- \text {venews }, k}-v e N S_{k, t}+\sum_{k=1}^{m} \gamma_{+ \text {venews }, k}+v e N S_{k, t}
\end{aligned}
$$

where $\delta_{E x p_{-} \text {Vol }}$ and $\delta_{\text {Unexp_Vol }}$ are the coefficients of expected and unexpected volume and $\delta_{\text {Exp_OI }}$ and $\delta_{\text {Unexp_OI }}$ are the coefficients expected and unexpected open interest and $N S_{k, t}=$ the component of news surprises. While $\gamma_{- \text {venews }, k}$ and $\gamma_{+ \text {venews }, k}$ are the coefficients of negative and positive news on volatility.

\section{Findings, Conclusion, and Scope of Future Research}

This paper examines the effect of macroeconomic news surprises on trading activity variables and returns volatility in the index futures market in India. For this purpose, we examined the index futures contract of CNX Nifty 50 traded on the National Stock Exchange (NSE), India, by using a dataset spanning for five years from January 2012 to December 2016. Estimating within the EGARCH framework, the results reveal that news surprises significantly affect returns volatility and that the news announcement of dividend yield, exchange rate, the repo rate, and index of industrial production 
are prima facie strong candidates affecting volatility. Besides, when trading activity variables were used as a proxy for information flows to check its impact on volatility, it was found that unexpected volume and open interest significantly affect volatility. However, when integrated into the EGARCH framework with news surprises, volume proxies lost their significance, indicating that news surprises are much stronger informational signals affecting return volatility.

The results of the study are of interest to various groups of market participants, namely policymakers, regulators, and investors. By investigating the reaction of the index futures market to news can offer insights on whether market participants respond to the views about how the economy operates. The study provides a clue to the fund managers and investors who can rebalance their portfolios by considering the return dynamics caused by the release of new news. Our study is comprehensive in scope by evaluating the responsiveness of several market activity variables, including the return, volatility, and trading volume against previous studies that have addressed the issue individually.

Future work may explore if global financial spillovers originating from different markets affect domestic financial markets, specifically the index futures. Other issues that also merit further consideration include using intraday data and see the sequences of news effects on market volatility within minutes around the news release.

\section{References}

Andersen, T. G., Bollerslev, T., Diebold, F. X., Vega, C., 2007. Real-time price discovery in global stock, bond and foreign exchange markets. Journal of International Economics 73, 251-277.

Balduzzi, P., Elton, E. J., Green, T. C., 2001. Economic news and bond prices: Evidence from the US Treasury market. Journal of financial and Quantitative analysis 36, 523-543.

Bessembinder, H., Seguin, P. J., 1993. Price volatility, trading volume, and market depth: Evidence from futures markets. Journal of Financial and Quantitative Analysis 28, 21-39.

Brzeszczyński, J., Gajdka, J., Kutan, A. M., 2015. Investor response to public news, sentiment and institutional trading in emerging markets: A review. International Review of Economics \& Finance 40, 338-352.

Chen, M. H., Tai, V. W., Yang, S. Y., 2011. Day Trading, Volatility and the Price-Volume Relationship: Evidence from the Taiwan Futures Market. Journal of finance Department of Banking and Finance.

Chen, M. H., Tai. V. W., 2014. The price discovery of day trading activities in futures market. Review of Derivatives Research 17.

Daigler, R. T., Wiley, M. K., 1999. The impact of trader type on the futures volatility-volume relation. The Journal of Finance 54, 2297-2316.

Elder, J., Miao, H., \& Ramchander, S., 2012. Impact of macroeconomic news on metal futures. Journal of Banking \& Finance 36, 51-65.

Epps, T. W., Epps, M. L., 1976. The stochastic dependence of security price changes and transaction volumes: Implications for the mixture-of-distributions hypothesis. Econometrica: Journal of the Econometric Society, 305-321.

Frankel, J. A., 2014. Effects of speculation and interest rates in a "carry trade" model of commodity prices. Journal of International Money and Finance 42, 88-112.

Frino, A., Webb, R. I., Zheng, H., 2012. Does international order flow contribute to price discovery in futures markets? Journal of Futures Markets 32, 1124-1143. 
Gallant, A. R., Rossi, P. E., Tauchen, G., 1992. Stock prices and volume. The Review of Financial Studies 5 , $199-242$

Garcia, D., 2013. Sentiment during recessions. The Journal of Finance 68, 1267-1300.

Gospodinov, N., Jamali, I., 2015. The response of stock market volatility to futures-based measures of monetary policy shocks. International Review of Economics \& Finance 37, 42-54.

Gulen, H., Mayhew. S., 2000. Stock index futures trading and volatility in international equity markets. Journal of Futures Markets 20, 661-685.

Harris, L., 1986. Cross-security tests of the mixture of distributions hypothesis. Journal of financial and Quantitative Analysis 21, 39-46.

Ho, K.Y., Shi, Y., Zhang. Z., 2017. Does news matter in China's foreign exchange market? Chinese RMB volatility and public information arrivals. International Review of Economics \& Finance 52, 302-321.

Hong, H., Yogo, M., 2012. What does futures market interest tell us about the macroeconomy and asset prices? Journal of Financial Economics, 105, 473-490.

Karali, B., Power, G. J., 2013. Short-and long-run determinants of commodity price volatility. American Journal of Agricultural Economics, 95, 724-738.

Kim, O., Verrecchia, R. E., 1991. Trading volume and price reactions to public announcements. Journal of Accounting Research 29, 302-321.

Kim, O., Verrecchia, R. E., 1997. Pre-announcement and event-period private information. Journal of Accounting and Economics 24, 395-419.

Lamoureux, C. G., Lastrapes, W.D., 1990. Heteroskedasticity in stock return data: Volume versus GARCH effects. The Journal of Finance 45, 221-229.

Nelson, D. B., 1991. Conditional heteroskedasticity in asset returns: A new approach. Econometrica: Journal of the Econometric Society 59, 347-370.

Nowak, S., Andritzky, J., Jobst, A., Tamirisa, N., 2011. Macroeconomic fundamentals, price discovery, and volatility dynamics in emerging bond markets. Journal of Banking \& Finance 35, 2584-2597.

Paiardini, P., 2014. The impact of economic news on bond prices: Evidence from the MTS platform". Journal of Banking \& Finance 49, 302-322. 